\title{
Use of Mobile Applications by Pregnant Women and Levels of Pregnancy Distress During the COVID-19 (Coronavirus) Pandemic
}

\author{
Sultan Özkan Şat ${ }^{1}$. $\cdot$ Şengül Yaman Sözbir ${ }^{1}$ \\ Accepted: 21 April 2021 / Published online: 30 April 2021 \\ (c) The Author(s), under exclusive licence to Springer Science+Business Media, LLC, part of Springer Nature 2021
}

\begin{abstract}
Objective Pregnancy and postpartum periods require continuity in care and counseling. During the pandemic process, telemedicine and telenursing applications have been used to meet the need for healthcare throughout the world, and skills in this area have been developed. This study aimed to identify the use of mobile applications by pregnant women in receiving health information, counseling, and healthcare during the COVID-19 pandemic and their distress levels during pregnancy. Methods This research was a descriptive cross-sectional study. The study was designed as an online survey administered between August 2020 and November 2020 via a questionnaire and the Tilburg Pregnancy Distress Scale (TPDS). A total of 376 women agreed to participate in the study. Women were included if they were literate, had a gestational age of $\geq 12$ th weeks, and accommodated within the Republic of Turkey's boundaries.

Results A total of $77.9 \%$ of participants reported using pregnancy-related mobile applications during the pandemic. The mean total Tilburg Pregnancy Distress Scale score was 24.09, and 37.2\% of the participants were found to be at risk for high distress according to the cut-off point. There was a significant difference between the change in receiving health services and the anxiety about coronavirus transmission and the Tilburg Pregnancy Distress Scale total score. $(\mathrm{p} \leq 0.05)$.

Conclusions This study helped understand the pandemic's impact on pregnancy distress and usage of mobile health applications by pregnant women during the pandemic. Also, our results indicate that a decrease in pregnant women receiving health services during this period. Mobile health applications appear to be usable for prenatal follow-ups because mobile applications are common among pregnant women during the COVID-19 pandemic.
\end{abstract}

Keywords COVID-19 $\cdot$ Mobile applications $\cdot$ Pregnancy $\cdot$ Distress $\cdot$ Anxiety $\cdot$ Depression $\cdot$ Nursing

\section{Significance}

What is already known on this subject? With the rapid spread of COVID-19, both people's daily life and health systems have been affected. This situation has revealed the need for telehealth services. Besides, a limited number of studies in the literature explore the impact of COVID-19 on pregnant women's distress levels. What this study adds? Findings from this study revealed that one-third of the pregnant women were at risk for pregnancy distress. More than

Sultan Özkan Şat

sultan.ozkan25@gmail.com

Şengül Yaman Sözbir

sengul.yaman@hotmail.com

1 Faculty of Health Sciences, Nursing Department, Gazi University, Emek mah. Bişkek Cad. 6. Cad. (eski 81. sokak) No:2, Çankaya, 06490 Ankara, Turkey three-quarters of the pregnant women used mobile applications related to pregnancy during the COVID-19 pandemic. Our study findings suggest that mobile health applications may be effective and usable tools to provide uninterrupted prenatal care during the COVID-19 pandemic.

\section{Introduction}

Following the COVID-19 pandemic caused by a new type of coronavirus called SARS COV-2, the delivery of and access to healthcare services have significantly changed (Fryer et al., 2020). Strategies for preventing the COVID19 pandemic, such as social distance, quarantine, and isolation, have led to difficulties in providing and receiving healthcare in this process (Turrentine et al., 2020). Almost all hospitals in Turkey have been turned into pandemic hospitals, resulting in fear of getting infected with COVID-19 
among patients who want to receive healthcare from these hospitals. Besides, the postponement of non-urgent health service requests to avoid the increase in the hospital and staff burden has increased people's concerns about their health conditions.

Pregnancy is a period of life in which women experience physiological, social, and psychological changes (Taşkın, 2016). The pregnancy period can be associated with psychological distress due to these changes. Psychological distress is often defined as depression, anxiety, and stress (Furber et al., 2009; Schuurmans \& Kurrasch, 2013). Psychological distress during pregnancy can result from many factors, such as family relationships, marital relationships, employment status, negative life experiences, difficulties and needs resulting from pregnancy, lack of social and emotional support during pregnancy, and social isolation (Çapık et al., 2015). Concerns about getting infected with COVID-19 and the prevention strategies from COVID-19 consisting of measures, such as social distance, quarantine, and isolation, pose risks to women with pregnancy in this period in terms of pregnancy distress.

Pregnancy and postpartum periods require continuity in care and counseling (Fryer et al., 2020; WHO, 2020a, 2020b). At the same time, these periods are sensitive periods where the line between illness and health becomes thinner. Therefore, while ensuring continuity in care and counseling, protecting this group from pregnancy distress and the risks of the COVID-19 pandemic is crucial (Dashraath et al., 2020; Fryer et al., 2020; Rasmussen et al., 2020). This situation has also increased the need for distance healthcare provision. Mobile health applications, which can be easily obtained through virtual application markets, have become an essential tool in meeting this need (Aziz et al., 2020; Fryer et al., 2020).

During the pandemic process, telemedicine and telenursing applications have been used to meet the need for healthcare throughout the world, and skills in this area have been developed (ACOG, 2020; Nanda et al., 2020). Especially in pregnancy and postpartum follow-up and care, telehealth programs have been created, widely used (Dashraath et al., 2020; Rochelson et al., 2020). Besides, a study has shown that telehealth applications are applicable in providing prenatal care (Aziz et al., 2020). In addition to these, leading international institutions, such as the American College of Obstetricians and Gynecologists and the Royal Australian and New Zealand College of Obstetricians and Gynecologists, recommend the use of telehealth applications in maintaining the prenatal and postnatal care of women with pregnancy (ACOG, 2020; RANZCOG, 2020). For this reason, this study was aimed to identify the status of using mobile health applications by pregnant women in receiving health information, counseling, and healthcare during the COVID19 pandemic and their distress levels during pregnancy.

\section{Methods}

\section{Research Design}

This study used a descriptive, cross-sectional design. The study was carried out using an online survey via social media (Twitter ${ }^{\circledR}$, Instagram ${ }^{\circledR}$, Facebook $^{\circledR}$, Whatsapp ${ }^{\circledR}$ ).

\section{Study Population and Sample}

The population of the study consisted of all women with pregnancy throughout Turkey during the COVID-19 pandemic. The sample size was calculated using the unknown population sampling calculation formula $(n=t 2 p q / d 2)$ (Sümbüloğlu \& Sümbüloğlu, 2012). In this context, the 2018 Turkey Demographic and Health Survey data was used as a reference to represent the Turkey population (TDHS, 2018, p.62). Accordingly, the sample size was calculated to be 358 pregnant women $(\mathrm{p}=0.37, \mathrm{q}=0.63, \mathrm{~d}=0.05$, and $\mathrm{t}=1.96)$. The study was completed with a total of 376 participants who accommodated within the boundaries of the Republic of Turkey, had a gestational age of $\geq 12$ th weeks, was literate, and volunteered to participate in the study.

\section{Data Collection Tools}

An online questionnaire form created by the researchers and the Tilburg Pregnancy Distress Scale were used to collect the data.

\section{The Online Survey Form}

This form, which the researchers developed, consists of 42 items aiming to determine data about participants' sociodemographic characteristics (i.e., age, education level), obstetric features (i.e., gravida, gestational weeks), and features of using mobile applications (i.e., using mobile applications, the purpose of using the applications, and the frequency of use).

\section{The Tilburg Pregnancy Distress Scale (TPDS)}

This scale was developed by Pop et al. (2011) to determine pregnancy distress (stress, anxiety, depression). The Turkish validity and reliability study of the scale was conducted by Çapık and Pasinlioğlu (2015). In the validity-reliability study of the scale, Cronbach's alpha value was found as 0.83 . In our study, Cronbach's alpha value of the scale was found as 0.76 .

The scale has a total of 16 items and a 4-point Likert type structure. Each item on the scale is graded with options, 
such as "very often" ( 0 points), "quite often" ( 1 point), "occasionally" ( 2 points), and "rarely or never" ( 3 points). Items $3,5,6,7,9,10,11,12,13,14$, and 16 on the scale are reversely coded. The lowest and highest scores obtained from the overall scale are 0 and 48 , respectively. The scale has two sub-dimensions: "negative affect" and "partner involvement". The negative affect sub-dimension is made up of items $3,5,6,7,9,10,11,12,13,14$, and 16 . The lowest and highest scores from this sub-dimension range between 0 and 33. The partner involvement sub-dimension consists of items $1,2,4,8$, and 15 . The scores from this sub-dimension vary between 0 and 15 .

The scale is administered to women with a gestational age of $\geq 12$ th weeks. The scale has a certain cut-off point. A total score of 28 and above enables making a diagnosis of women with pregnancy at risk for distress (depression, anxiety, and stress).

\section{Procedure}

The study was carried out online during the COVID-19 pandemic between August and November 2020. In this context, the online survey was spread first by reaching out to people following the researchers' social media accounts. The online survey link was also shared on social media accounts about pregnancy and birth, and thus, women with pregnancy following these pages were reached. Responding to the online survey took approximately $10-15 \mathrm{~min}$ for each participant.

\section{Data Analysis}

Data were analyzed using SPSS 23.0 (Statistical Package for Social Sciences, version 23.0, for Windows) software package. A Kolmogorov-Smirnov test was used to test whether the data were normally distributed. Descriptive statistical methods such as the mean, standard deviation, number, percentage, and the Student's t-test and chi-square tests were used to analyze the data.

Multiple logistic regression was used to calculate to identify factors associated with mobile applications usage of pregnant women and level of pregnancy distress. A few steps were taken to identify these factors. First, we used forward stepwise regression to remove those variables with $\mathrm{p}$ values $>0.05$. Second, age, education level, working status, economic status, the longest place of residence during the COVID-19 pandemic, gestational week, gravida, previous pregnancy loss, the desired status of current pregnancy, type of getting pregnant, status of experiencing any complications in the current pregnancy, risky pregnancy situation, the situation of worrying about coronavirus transmission and change in health service receiving during the COVID-19 pandemic were included in the models. Finally, we included age, education level, and status of experiencing any complications in the current pregnancy as independent variables in the multiple regression model to predict mobile application usage. Similarly, we included the longest place of residence during the COVID-19 pandemic, the status of experiencing any complications in the current pregnancy and worrying about coronavirus transmission as independent variables in the multiple regression model to predict pregnancy distress.

\section{The Ethical Aspect of the Study}

At the outset, the permission of the Turkish Republic Scientific Research Platform of the Ministry of Health was obtained to carry out a study related to the pandemic process. The University Ethics Committee's approval was obtained (Research Code No: 2020-497). The study has been performed following the ethical standards laid down in the 1964 Declaration of Helsinki and its later amendments. During the online survey implementation phase, the participants were first supplied with a page giving information about the study. They read this information on the page first, and then they started the survey after checking a checkbox that indicated they agreed to participate in the survey. All participants gave their informed consent before their inclusion in the study. No personal information was requested from the participants. Their responses were considered anonymous, and the researchers did not see whom the answers belonged to. All data obtained from the participants were kept confidential and stored at an e-mail address accessible only to researchers.

\section{Results}

\section{Demographic and Obstetric Characteristics}

Table 1 shows the demographic and obstetric characteristics of the participants. The mean age of the participants was $27.6 \pm 4.74$, ranging between 18 and 45 . Also, $44.9 \%$ were high school graduates, $69.9 \%$ were not employed, and 55.9\% perceived a middle economic status level. The participants' mean gestational age was $28.09 \pm 8.10$ weeks, which ranged between 12 and 41 . According to the findings, $43.4 \%$ of the participants were experiencing their first pregnancy, $82.7 \%$ had not experienced a previous pregnancy loss, $88.6 \%$ had a planned pregnancy, $97.9 \%$ got pregnant naturally, and $71.5 \%$ did not experience any complications in their current pregnancy (Table 1).

\section{Characteristics of the Participants Regarding the COVID-19 Pandemic Process}

Participants' characteristics regarding the COVID 19 pandemic process are shown in Table 2. According to the results, $3.5 \%$ of the participants and their relatives of $18.6 \%$ had a history of COVID-19 infection, $51.3 \%$ were very anxious 
Table 1 Demographic and obstetric characteristics of the participants

Demographic characteristics

\begin{tabular}{lll}
\hline & $\bar{X} \pm$ SD & Min-Max \\
\hline Age & $27.65 \pm 4.74$ & $18-45$ \\
\hline Education Level & Number (n=376) & 19.5 \\
Elementary school & 73 & 44.9 \\
High school & 169 & 35.6 \\
Undergraduate or above & 134 \\
Working status & & 30.1 \\
Yes & 113 \\
No & 263 \\
Economic status & & 69.9 \\
Above average & 86 \\
Average & 210 \\
Below average & 80 & 22.9 \\
The longest place of residence during the Covid-19 pandemic & & 55.9 \\
Metropolis & 86 & 21.3 \\
City & 156 & 22.9 \\
District & 72 & 41.5 \\
Village-town & 62 & 19.1 \\
\hline Obstic chacteistics & & 16.5 \\
\hline
\end{tabular}

Obstetric characteristics

\begin{tabular}{|c|c|c|}
\hline & $\bar{X} \pm \mathrm{SD}$ & Min-Max \\
\hline Gestational week & $28.09 \pm 8.10$ & $12-41$ \\
\hline Gravida & Number $(n=376)$ & $\%$ \\
\hline 1 & 163 & 43.4 \\
\hline 2 & 149 & 39.6 \\
\hline 3 & 50 & 13.3 \\
\hline 4 & 14 & 3.7 \\
\hline \multicolumn{3}{|l|}{ Previous pregnancy loss } \\
\hline Yes & 65 & 17.3 \\
\hline No & 311 & 82.7 \\
\hline \multicolumn{3}{|l|}{ Desired status of current pregnancy } \\
\hline Intended & 333 & 88.6 \\
\hline Unintended & 43 & 11.4 \\
\hline \multicolumn{3}{|l|}{ Type of getting pregnant } \\
\hline Naturally & 368 & 97.9 \\
\hline Assisted reproductive techniques & 8 & 2.1 \\
\hline \multicolumn{3}{|c|}{ Status of experiencing any complications in the current pregnancy } \\
\hline Yes & 107 & 28.5 \\
\hline No & 269 & 71.5 \\
\hline \multicolumn{3}{|l|}{ The most common complications* } \\
\hline Hyperemesis gravidarum & 65 & 61.3 \\
\hline Hemorrhage & 43 & 40.6 \\
\hline Pain & 33 & 31.1 \\
\hline \multicolumn{3}{|l|}{ Risky pregnancy situation } \\
\hline Yes & 48 & 12.8 \\
\hline No & 328 & 87.2 \\
\hline \multicolumn{3}{|l|}{ The most common pregnancy risks** } \\
\hline Gestational diabetes mellitus & 14 & 30.4 \\
\hline Infection & 12 & 26.1 \\
\hline
\end{tabular}


Table 1 (continued)

\begin{tabular}{lll}
\hline Blood diseases & 10 & 19.6 \\
Gestational hypertension & 6 & 13.1 \\
Small for gestational age & 6 & 13.1 \\
\hline
\end{tabular}

*Those who stated that she experienced any complications in her current pregnancy answered. $\mathrm{n}$ is replicated as pregnant women can choose more than one statement

**Those who stated that there was a risky situation in their current pregnancy answered. $\mathrm{n}$ is replicated as pregnant women can choose more than one statement

about coronavirus transmission, $94.4 \%$ had a decrease in their receiving healthcare services during the pandemic process, and $72.3 \%$ were afraid of having no access to health services (Table 2).

In our study, the effects of the anxiety about coronavirus transmission on daily life were examined. In this context, $75.9 \%$ of the participants reported that they always wore a mask while going out, $64.7 \%$ expressed that their frequency of handwashing increased, 59.7\% did not visit anyone, $56.8 \%$ did not accept guests, $55.9 \%$ strictly practiced a $2-\mathrm{m}$ social distance rule, and $49.1 \%$ did not go out at all (Table 2).

In our study, $89.6 \%$ of the participants who stated that there was a decrease in the rate of health services they received during the pandemic process were afraid of getting infected in the hospital, $57.9 \%$ said the hospital they visited was a pandemic hospital, and $6.8 \%$ reported the hospital that they visited did not provide pregnancy outpatient services (Table 2).

\section{The Characteristics of the Participants' Mobile Application Usage}

The characteristics of the participants'mobile application usage during the COVID-19 pandemic are shown in Table 3. According to the results, $77.9 \%$ of participants reported using pregnancy-related mobile applications during the pandemic, $47 \%$ stated that they spent approximately less than an average of $60 \mathrm{~min}$ for a few days a week, $82.8 \%$ reported that they used mobile applications to learn about the normal changes that can be seen during pregnancy, and $29.5 \%$ used them to get information about COVID-19 and pregnancy, birth, and postpartum process (Table 3 ).

In our study, $96.5 \%$ of the participants stated that using mobile applications during the pandemic was beneficial. Also, by using mobile applications, $84 \%$ wanted to receive health services during the pandemic, $97.9 \%$ wanted to ask questions to a physician/nurse, $72.6 \%$ wanted to get counseling via video conferencing, and $91 \%$ wanted to exchange ideas with women with pregnancy who were in similar situations (Table 3).

Multiple logistic regression analysis was conducted to identify factors associated with pregnant women's mobile application usage. Accordingly, age, education level, and status of experiencing any complications in the current pregnancy predicted the mobile application usage positively and significantly (Table 5).

\section{Results Related to the Pregnancy Distress Levels of the Participants}

Findings of the participants obtained from the Tilburg Pregnancy Distress Scale are shown in Table 4. The mean Tilburg Pregnancy Distress Scale's overall score was $24.09 \pm 7.29$, and $37.2 \%$ of the participants were found to be at risk for high distress according to the cut-off point (Table 4).

A statistically significant difference was found in our study between the change in receiving health services and the anxiety about coronavirus transmission and the mean Tilburg Pregnancy Distress Scale overall score $(\mathrm{p} \leq 0.05)$. Accordingly, the mean scale score of those who stated a change in receiving health services increased, and they were determined to be at risk for distress. Similarly, the mean scale scores of those who expressed their concerns about coronavirus transmission also increased, and they were found to be at risk for distress (Table 4).

Multiple logistic regression analysis was conducted to identify factors associated with pregnancy distress level. Accordingly, the longest place of residence during the Covid-19 pandemic and the situation of worrying about coronavirus transmission predicted the level of pregnancy distress positively and significantly. However, experiencing any complications in the current pregnancy negatively and significantly predicted the level of pregnancy distress (Table 5).

\section{Discussion}

The COVID-19 pandemic has rapidly affected the whole world and profoundly impacted people's daily lives and their demands for healthcare and the supply of healthcare services. Almost all pregnant women (90.4\%) in our study were concerned about being infected with coronavirus and that this situation affected pregnant women's daily lives. Most pregnant women stated that they obeyed protective measures (mask, distance, and hygiene rules) to protect against 
Table 2 Characteristics of the participants regarding the COVID-19 pandemic process

\begin{tabular}{|c|c|c|}
\hline & Number & $\%$ \\
\hline \multicolumn{3}{|l|}{ Situations Experienced During the COVID-19 pandemic* $(n=417)$} \\
\hline I had the COVID-19 (coronavirus) infection & 13 & 3.5 \\
\hline My relatives had the COVID-19 (coronavirus) infection & 70 & 18.6 \\
\hline I lost my relatives due to the COVID-19 (coronavirus) infection & 9 & 2.4 \\
\hline I was laid off during the COVID-19 (coronavirus) pandemic & 2 & 0.5 \\
\hline My partner was laid off during the COVID-19 (coronavirus) pandemic & 14 & 3.7 \\
\hline I was subjected to violence from my partner during the COVID-19 (coronavirus) pandemic & 1 & 0.3 \\
\hline I experienced financial difficulties during the COVID-19 (coronavirus) pandemic process & 52 & 13.8 \\
\hline I have not experienced any of them & 256 & 68.1 \\
\hline \multicolumn{3}{|l|}{ The situation of worrying about coronavirus transmission $(n=376)$} \\
\hline Yes. Too much & 193 & 51.3 \\
\hline Yes. Very little & 147 & 39.1 \\
\hline No. Never & 36 & 9.6 \\
\hline \multicolumn{3}{|l|}{ The effects of worrying about coronavirus transmission on daily life $* *(n=1635)$} \\
\hline I began staying at home & 167 & 49.1 \\
\hline I did not accept guests at home & 193 & 56.8 \\
\hline I did not go to visit & 203 & 59.7 \\
\hline I did not meet with anyone less than $2 \mathrm{~m}$ away & 190 & 55.9 \\
\hline When I needed to go out, I always wore a mask & 258 & 75.9 \\
\hline I separated our bedroom with my partner & 25 & 7.4 \\
\hline My hand washing frequency has increased & 220 & 64.7 \\
\hline I always used gloves when I had to go out & 71 & 20.9 \\
\hline I did not go to the prenatal follow-ups that I should normally have & 50 & 14.7 \\
\hline I started to pay more attention to what I eat and drink & 93 & 27.4 \\
\hline My daily sleep time increased; I started to sleep more than before & 50 & 14.7 \\
\hline The time I spend on the internet has increased compared to the past & 115 & 33.8 \\
\hline \multicolumn{3}{|l|}{ Change in health service receiving during the COVID-19 pandemic $(n=376)$} \\
\hline Yes & 235 & 62.5 \\
\hline - Increased & 13 & 5.6 \\
\hline - Decreased & 222 & 94.4 \\
\hline No & 141 & 37.5 \\
\hline \multicolumn{3}{|l|}{ Reasons for receiving more health care service during the COVID-19 Pandemic $* * *(n=15)$} \\
\hline I felt constantly needed health examinations because I was afraid of getting sick & 7 & 53.9 \\
\hline I constantly had an ultrasound because I was concerned about my infant's health & 8 & 61.5 \\
\hline \multicolumn{3}{|l|}{ Reasons for receiving less health care service during the COVID-19 pandemic $* * * *(n=361)$} \\
\hline I was afraid of getting COVID-19 infection from the hospital & 198 & 89.6 \\
\hline The hospital I went to became a pandemic hospital & 128 & 57.9 \\
\hline The hospital I went to did not provide pregnancy outpatient services & 15 & 6.8 \\
\hline My doctor had the COVID-19 (coronavirus) infection & 4 & 1.8 \\
\hline My partner did not allow me to go to the hospital & 11 & 5.0 \\
\hline I could not go to the hospital because of financial difficulties & 5 & 2.3 \\
\hline \multicolumn{3}{|l|}{ Fear of failing to access health services during the Covid-19 Pandemic Process $(n=376)$} \\
\hline Yes & 272 & 72.3 \\
\hline No & 104 & 27.7 \\
\hline
\end{tabular}

$*_{\mathrm{n}}$ is replicated as pregnant women can choose more than one statement

**Those who expressed concern about coronavirus transmission answered. $\mathrm{n}$ is replicated as pregnant women can choose more than one statement

***Those who stated that they receive more healthcare services receiving during the Covid-19 pandemic, answered. $\mathrm{n}$ is replicated as pregnant women can choose more than one statement

****Those who stated that they receive less healthcare services receiving during the Covid-19 pandemic, answered. $\mathrm{n}$ is replicated as pregnant women can choose more than one statement 
Table 3 The Characteristics of the participants' mobile application usage

\begin{tabular}{|c|c|c|}
\hline & Number & $\%$ \\
\hline \multicolumn{3}{|l|}{ Mobile application usage during the COVID-19 pandemic $(\mathrm{n}=376)$} \\
\hline Using & 293 & 77.9 \\
\hline Not using & 83 & 22.1 \\
\hline \multicolumn{3}{|c|}{ Frequency of Using Mobile Applications During the Covid-19 Pandemic $(n=293)$} \\
\hline Less than $60 \mathrm{~min} / \mathrm{each}$ day & 65 & 23.0 \\
\hline More than $60 \mathrm{~min} / \mathrm{each}$ day & 21 & 7.4 \\
\hline Less than $60 \mathrm{~min} / \mathrm{a}$ few days in a week & 133 & 47.0 \\
\hline More than $60 \mathrm{~min} / \mathrm{a}$ few days in a week & 59 & 20.8 \\
\hline Others & 15 & 1.8 \\
\hline \multicolumn{3}{|c|}{ Purpose of using mobile application during the Covid-19 pandemic $*(n=1670)$} \\
\hline Normal changes during pregnancy & 236 & 82.8 \\
\hline Risks and diseases that can be experienced during pregnancy & 219 & 76.8 \\
\hline Infant's development in the womb & 221 & 77.5 \\
\hline Calculation of the estimated birth date & 135 & 47.4 \\
\hline Schedule for medical examinations and tests & 92 & 32.3 \\
\hline Nutrition in pregnancy & 105 & 36.8 \\
\hline Pregnancy and marital relationship & 43 & 15.1 \\
\hline Sexual intercourse in pregnancy & 53 & 18.6 \\
\hline To get prenatal information & 106 & 37.2 \\
\hline Delivery & 133 & 46.7 \\
\hline Newborn care & 88 & 30.9 \\
\hline Infant nutrition/feeding & 62 & 21.8 \\
\hline Postpartum recovery process & 54 & 18.9 \\
\hline Contraceptive methods & 39 & 13.7 \\
\hline COVID-19, pregnancy, delivery, and postpartum process & 84 & 29.5 \\
\hline \multicolumn{3}{|c|}{ Was using mobile applications during the pandemic beneficial?** $(\mathrm{n}=293)$} \\
\hline Yes & 283 & 96.5 \\
\hline No & 10 & 3.5 \\
\hline \multicolumn{3}{|c|}{ Would you like to want to receive health services via mobile applications during the COVID-19 pandemic? $(\mathrm{n}=376)$} \\
\hline Yes & 316 & 84.0 \\
\hline No & 60 & 16.0 \\
\hline \multicolumn{3}{|c|}{ I would like to want to ask questions to a physician/nurse via mobile applications. $(\mathrm{n}=376)$} \\
\hline Yes & 368 & 97.9 \\
\hline No & 8 & 2.1 \\
\hline \multicolumn{3}{|c|}{ I would like to be able to want to get counseling via video conferencing by using mobile applications. $(\mathrm{n}=376)$} \\
\hline Yes & 273 & 72.6 \\
\hline No & 103 & 27.4 \\
\hline \multicolumn{3}{|c|}{ I would like to exchange ideas with other pregnant women who are in a similar situation to me. $(n=376)$} \\
\hline Yes & 342 & 91.0 \\
\hline No & 34 & 9.0 \\
\hline
\end{tabular}

*Those who stated that they used a mobile application answered. $\mathrm{n}$ is replicated as pregnant women can choose more than one statement

**Those who stated that they used a mobile application answered

COVID-19, about half of them did not go out during this period, and more than half of them avoided socializing by canceling visits and guest admissions. Thirteen participants
(5.6\%) in the study stated that they received more health services during this period due to anxiety about their health status. These pregnant women stated that they felt they 
Table 4 Results related to the Tilburg Pregnancy Distress Scale

\begin{tabular}{|c|c|c|c|c|c|c|}
\hline & & \multicolumn{5}{|c|}{ Tilburg Pregnancy Distress Scale } \\
\hline & & \multicolumn{2}{|l|}{$\bar{X} \pm \mathrm{SD}$} & \multicolumn{2}{|l|}{ Min } & $\operatorname{Max}$ \\
\hline \multicolumn{2}{|l|}{ Total scale score } & \multicolumn{2}{|l|}{$24.09 \pm 7.29$} & \multicolumn{2}{|l|}{4} & 38 \\
\hline \multicolumn{3}{|l|}{ During COVID-19 pandemic } & & \multicolumn{3}{|c|}{ Statistics } \\
\hline \multicolumn{2}{|l|}{ Change in health service receiving } & \multicolumn{2}{|l|}{$\bar{X} \pm \mathrm{SD}$} & \multicolumn{2}{|l|}{$\mathrm{F}$} & $\mathrm{p}$ \\
\hline \multicolumn{2}{|l|}{ Yes $(n=235)$} & \multicolumn{2}{|l|}{$26.29 \pm 5.74$} & \multicolumn{2}{|l|}{33.864} & $0.000^{*}$ \\
\hline \multicolumn{2}{|l|}{ No $(n=141)$} & \multicolumn{2}{|l|}{$20.42 \pm 8.11$} & & & \\
\hline \multicolumn{7}{|c|}{ The situation of worrying about coronavirus transmission } \\
\hline Yes $(n=340)$ & & \multicolumn{2}{|l|}{$24.11 \pm 7.50$} & \multicolumn{2}{|l|}{5.672} & $0.018^{*}$ \\
\hline No $(n=36)$ & & \multicolumn{4}{|l|}{$23.88 \pm 5.03$} & \\
\hline \multirow{3}{*}{$\begin{array}{l}\text { Change in health service } \\
\text { receiving }\end{array}$} & \multicolumn{6}{|c|}{ According to the cut-off point } \\
\hline & \multicolumn{2}{|c|}{ Low distress } & \multicolumn{2}{|c|}{ High distress } & \multicolumn{2}{|c|}{ Statistics } \\
\hline & $n$ & $\%$ & $\mathrm{n}$ & $\%$ & $\overline{\chi^{2}}$ & $\mathrm{p}$ \\
\hline Yes & 127 & 54.0 & 108 & 46.0 & 20.405 & $0.000 *$ \\
\hline No & 109 & 77.3 & 32 & 22.7 & & \\
\hline Total & 236 & 62.8 & 140 & 37.2 & & \\
\hline
\end{tabular}

*p $\leq 0.05$

Table 5 Multiple regression analysis considering the variables with acceptable significance predicting mobile applications usage and Tilburg Pregnancy Distress

\begin{tabular}{|c|c|c|c|c|c|c|c|}
\hline Variables & $\mathrm{B}$ & $\mathrm{SE}_{\mathrm{B}}$ & Beta & $\mathrm{t}$ & $\mathrm{p}$ & $\mathrm{R} 2$ & $\mathrm{~F}$ \\
\hline Mobile applications usage (Constant) & 1.157 & 0.142 & - & 8.156 & $0.000^{*}$ & 0.109 & $(4-371)=12.489$ \\
\hline Age & 0.073 & 0.023 & 0.159 & 3.227 & $0.001 *$ & & \\
\hline Education level & 0.045 & 0.021 & 0.107 & 2.108 & $0.036^{*}$ & & \\
\hline Status of experiencing any complications in the current pregnancy & 0.147 & 0.045 & 0.159 & 3.259 & $0.001 *$ & & \\
\hline Tilburg Pregnancy Distress Scale (Constant) & 1.090 & 0.084 & - & 5.920 & $0.000^{*}$ & 0.106 & $(3-372)=15.749$ \\
\hline The longest place of residence during the Covid-19 pandemic & 0.113 & 0.024 & 0.234 & 4.713 & $0.000^{*}$ & & \\
\hline Status of experiencing any complications in the current pregnancy & -0.191 & 0.71 & -0.132 & -2.678 & $0.008^{*}$ & & \\
\hline The situation of worrying about coronavirus transmission & 0.157 & 0.036 & 0.214 & 4.327 & $0.000^{*}$ & & \\
\hline
\end{tabular}

$* \mathrm{p} \leq 0.05$

constantly needed health examinations. They were afraid of getting sick and constantly had an ultrasound because they were concerned about the fetus's health. In a study examining the health concerns and behavioral changes of pregnant women during the COVID-19 pandemic, $50.7 \%$ of pregnant women were concerned about their health, and that $63.4 \%$ were concerned about the fetus's health reported. In the same study, that $35.2 \%$ of the pregnant women isolated themselves, and that $70.4 \%$ avoided socialization were reported (Corbett et al., 2020). In another study, that 58\% of the pregnant women isolated themselves due to the fear of getting infected with the virus was reported (Karavadra et al., 2020). The findings of our study are similar to those of the cited studies in this respect.
In managing the pandemic process, hospital and health institution visits, including routine health checks, be limited to emergency and critical situations (Hussein, 2020). Indeed, our study revealed that during the COVID-19 pandemic, there was a change in the frequency of receiving health services among pregnant women. Almost all pregnant women (94.4\%) who reported a change stated a decrease in their receiving health services during this period. In our study, more than half of the women stated the hospital they visited for prenatal follow-ups was a pandemic hospital (57.9\%), very few of them stated there were no pregnancy outpatient services in the hospital they visited (6.8\%), 89.6\% were afraid of getting an infection from the hospital, $14.7 \%$ did not go to the prenatal follow-ups they should normally have. 
Others stated that they could not get healthcare services during this period because their husband did not allow them to. In previous pandemic periods, access to reproductive health and antenatal healthcare services decreased, and many undesirable complications emerged due to the situation (Hall et al., 2020; Riley et al., 2020). A study in the literature stated that people might be unwilling to go to health institutions during the pandemic for fear that they might get infected (Riley et al., 2020). In a study conducted in Turkey during the COVID-19 pandemic, 20\% of pregnant women were reported to ignore their regular prenatal follow-ups (Kahyaoğlu Süt \& Küçükkaya, 2020). A study conducted in Wuhan, where the coronavirus first appeared, stated that $41.9 \%$ of pregnant women refused to go to the hospital for fear of getting infected and that they wanted to postpone prenatal care and hospitalizations (Liu et al., 2020). Another study carried out in China stated that more than $40 \%$ of the pregnant women were afraid of antenatal controls performed in the hospital, and $20 \%$ were afraid of getting an infection from any consultation performed in the hospital (Wu et al., 2020). In another study conducted in Israel reported that $59.2 \%$ of pregnant women were afraid of getting infected with coronavirus and that $68.7 \%$ were concerned about pregnancy controls (Ben-Ari et al., 2020). Our study's findings are similar to those of the literature regarding pregnant women's anxiety about receiving face-to-face prenatal care due to the fear of infection in the COVID-19 pandemic. This situation is serious in that it may lead to more severe and longterm consequences due to failure/refusing to receive prenatal care other than the problems caused by the pandemic itself before, during, and after delivery. Riley et al. determined that a $10 \%$ decrease in receiving prenatal and neonatal care services would lead to an increase of 1.7 million women with major obstetric complications and 2.6 million newborns with major complications, thereby resulting in the death of an additional 28,000 women and 168,000 newborns (Riley et al., 2020). Therefore, that important to provide prenatal care and counseling through telehealth tools, including mobile health applications, to reduce the negative effects of the COVID-19 pandemic on healthcare services before, during, and after delivery is thought.

One-third of the pregnant women in our study stated that they were afraid of failing to access health services during the pandemic. World Health Organization has defined the health services provided before, during, and after delivery as essential health services that should continue uninterruptedly during the COVID-19 pandemic process (WHO, ). Telehealth tools that allow the distance provision of these services should be adopted (ACOG, 2020; Hall et al., 2020; Riley et al., 2020; Weigel et al., 2020). Our study determined that one-third of the pregnant women spent more time on the internet than before, and more than three quarters (77.9\%) used mobile applications related to pregnancy during the
COVID-19 pandemic. While most pregnant women stated that they used mobile applications to get information about the normal changes that can be seen in pregnancy, approximately one-third of them used mobile applications to obtain information about pregnancy, birth, and the postpartum process in the COVID-19 pandemic. There were no studies in the literature regarding the use of mobile applications by pregnant women during the pandemic.

Almost all pregnant women in our study stated that using mobile applications in this process was beneficial. $84 \%$ of pregnant women expressed that they wanted to receive services through mobile applications during the pandemic process, almost all of them wanted to ask questions to physicians or nurses via mobile applications, one-third wanted to receive consultancy services through video conferencing, and $91 \%$ stated that they wanted to exchange ideas with pregnant women in similar situations. Besides, age, education level, and status of experiencing any complications in the current pregnancy positively and significantly predicted mobile application usage. There were no studies in the literature regarding the associated factors with mobile application usage during the pandemic. Mobile applications are mostly used by young and young adults who use mobile phones actively. The fact that the pregnant women in our study were between the ages of 18-45 revealed the determining effect of age on mobile application use. On the other hand, since education level is a factor affecting the health literacy and use of technological devices, education level has also been a factor determining the use of mobile applications related to health. Problematic health situations of pregnant women are also determinant in seeking health care. In this context, having problems during pregnancy has been determinant in seeking help via mobile application when the hospital or doctor/nurse cannot be reached directly during the pandemic process.

A tiny part of prenatal care involves procedures that require going to a health institution (i.e.ultrasound, laboratory tests, vaccination), and most of it includes education of pregnant women, answering questions, and counseling. For this reason, continuing the follow-ups through telehealth applications, including mobile applications, during pregnancy is recommended (Weigel et al., 2020). Midwives in England were reported to continue providing antenatal and postnatal care using mobile and web-based technologies (Bick, 2020). The pregnant women participating in our study had a positive approach to getting healthcare services via mobile applications. Providing distance healthcare services via mobile applications during the pandemic has the potential to alleviate the anxiety of pregnant women about the failure to access health services. Therefore, integrating mobile applications into the health system and using them in prenatal care and consultancy will ensure these uninterrupted services. 
The prevalence of anxiety and depression may increase during pregnancy and the postpartum period due to the socio-economic effects of social isolation and pandemic caused by the COVID-19 pandemic (UNFPA, 2020). Our study determined that one-third of the pregnant women were at risk for distress according to the recommended cut-off value. Also, the mean Tilburg Pregnancy Distress Scale scores of the participants who stated a change in their receiving health services during the pandemic were statistically significantly higher than those who reported no change $(p<0.05)$. Similarly, the mean scores of the participants who stated that they were worried about coronavirus transmission were statistically significantly higher than those who stated they were not concerned about coronavirus transmission $(\mathrm{p}<0.05)$. Besides, the longest place of residence during the Covid-19 pandemic and the situation of worrying about coronavirus transmission predicted the level of pregnancy distress positively and significantly. Cities are crowded compared to villages and towns, which increases the possibility of virus spread during the pandemic process. Therefore, the residential place where pregnant women live has been determinant in the distress of COVID-19 during pregnancy. Being afraid of virus transmission was also found to be a determinant of pregnancy distress. However, experiencing any complications in the current pregnancy negatively and significantly predicted the level of pregnancy distress. This result is an expected because complications during pregnancy increase distress due to the possibility of miscarriage, premature birth, harm to the baby or mother.

Pregnant women who experienced a change in their receiving health services during the pandemic and those concerned about coronavirus transmission were at risk for distress. According to a study, COVID-19 increases pregnant women's anxiety levels (Corbett et al., 2020). A study conducted to determine the psychological effects of COVID-19 on pregnant women reported that more than half of the pregnant women (53\%) experienced higher anxiety than normal and that COVID-19 had a moderate psychological effect on pregnant women (Saccone et al., 2020). Another study conducted to evaluate the current and state anxiety of pregnant women in the COVID-19 pandemic stated that $62.6 \%$ of pregnant women were at risk for anxiety (Yassa et al., 2020). A study conducted to determine the prevalence of anxiety, depression, and factors affecting pregnant women during the COVID-19 pandemic reported that $64.5 \%$ of pregnant women experienced anxiety and that $56.3 \%$ had depression. Also, the study found that feeling discomfort during hospital controls, having knowledge of COVID-19, and getting information from the healthcare personnel were among the factors related to anxiety (Kahyaoğlu Süt \& Küçükkaya, 2020). Berthelot et al. stated that pregnant women reported more distress and psychiatric symptoms during the pandemic (Berthelot et al., 2020). The findings of our study are similar to those of the literature. Considering the negative effects of uncontrolled anxiety, depression, and stress during pregnancy on maternal and fetal health, the distress experienced by pregnant women should be addressed. Reducing the fear of getting infected and the fear of failing to access health services to the lowest possible level will be effective in lowering pregnant women's distress levels. Mobile health applications are thought to be the most effective and usable tool in the pandemic conditions we have been going through.

Our findings should be interpreted within the context of the limitations and strengths of the study. One of our study's strengths is that the first study investigating the use of mobile applications in the health care system in Turkey during the pandemic. Another strength of the study is that our study reflects nationwide data on pregnant women as the study was conducted online. According to the Turkish Statistical Institute Information Technologies Usage Survey, the internet usage rate is $79.0 \%$ among individuals aged $16-74$ in 2020 . When the internet usage rate is analyzed by gender, this rate is $84.7 \%$ for men and $73.3 \%$ for women (TSI, 2020). Therefore, we consider that online surveys are a usable method for pregnant women during the pandemic process. On the other hand, as our study design is crosssectional, we cannot offer definitive evidence about findings. Due to this reason, causality in this study cannot be explained definitively. Although our study sample consists of nationwide participants, our study findings cannot be generalized to pregnant women with low education and income levels, not using smartphones and social media.

\section{Conclusion}

Our study was conducted to determine the use of mobile health applications by pregnant women during the pandemic and their distress levels during pregnancy. Our study revealed that the pandemic process significantly affected pregnant women's daily lives and receiving health services. Our results were also revealed that more than three-quarters of the pregnant women used mobile applications related to pregnancy such as Day to Day Pregnancy ${ }^{\circledR}$, Pregnancy Week by Week ${ }^{\circledR}$, Happy Mom ${ }^{\circledR}$, While Waiting for My Baby ${ }^{\circledR}$ and that one-third of them were at risk for pregnancy distress according to the recommended cut-off value.

In line with these results of our study, we recommend that mobile applications should be integrated into the health system so that pregnant women can receive adequate and uninterrupted prenatal care during the pandemic. For this purpose, the mobile applications can be technically integrated into the data processing systems used in the hospital. To integrate into the hospital systems, feasibility studies should be initiated. Healthcare professionals should develop their mobile applications in line with up-to-date 
and evidence-based information. So, prenatal follow-ups could be safely done using mobile applications. Also, we recommend that psychological care and counseling within the provision of distance healthcare services should be taken into account so that the negative effects of the new lifestyle imposed by the pandemic conditions on pregnant women's psychology can be taken under control.

Author Contributions Sultan Özkan Şat: Conception and Design, Analysis and Interpretation of Data, Drafting the Article. Şengül Yaman Sözbir: Conception and Design, Analysis and Interpretation of Data, Drafting the Article, Revising it critically for important intellectual content.

Funding There was not receive any sponsor support at any stage of the study.

\section{Declarations}

Conflict of Interest There is no conflict of interest between the authors.

Consent to Participate Prior to study consent to participate was obtained.

Ethical Approval Ethical approval was obtained from Gazi University Ethics Committee. Research Code No: 2020-497.

\section{References}

American College of Obstetricians and Gynecologists (ACOG). (2020). Committee opinion number 798 implementing telehealth in practice. Obstetrics and Gynecology, 135(2), e73-e79

Aziz, A., Zork, N., Aubey, J. J., Baptiste, C. D., D’Alton, M. E., Emeruwa, U. N., Fuchs, K. M., Goffman, D., Gyamfi-Bannerman, C., Haythe, J. H., LaSala, A. P., Madden, N., Miller, E. C., Miller, R. S., Monk, C., Moroz, L., Ona, S., Ring, L. E., Sheen, J., ... Friedman, A. M. (2020). Telehealth for high-risk pregnancies in the setting of the COVID-19 pandemic. American Journal of Perinatology, 37(8), 800-808. https://doi.org/10.1055/s-0040-1712121

Ben-Ari, O. T., Chasson, M., Sharkia, S. A., \& Weiss, E. (2020). Distress and anxiety associated with COVID-19 among Jewish and Arab pregnant women in Israel. Journal of Reproductive and Infant Psychology, 38(3), 340-348. https://doi.org/10.1080/02646 838.2020.1786037

Berthelot, N., Lemieux, R., Garon-Bissonnette, J., Drouin-Maziade, C., Martel, É., \& Maziade, M. (2020). Uptrend in distress and psychiatric symptomatology in pregnant women during the coronavirus disease 2019 pandemic. Acta Obstetricia et Gynecologica Scandinavica, 99(7), 848-855. https://doi.org/10.1111/aogs.13925

Bick, D. (2020). COVID-19: 2020 is the International year of the midwife. Midwifery, 85, 102719. https://doi.org/10.1016/j.midw.2020. 102719

Corbett, G. A., Milne, S. J., Hehir, M. P., Lindow, S. W., \& O'connell, M. P. (2020). Health anxiety and behavioral changes of pregnant women during the COVID-19 pandemic. European Journal of Obstetrics \& Gynecology and Reproductive Biology, 249, 96-97. https://doi.org/10.1016/j.ejogrb.2020.04.022

Çapık, A., \& Pasinlioğlu, T. (2015). Validity and reliability study of the Tilburg Pregnancy Distress Scale into Turkish. Journal of
Psychiatric and Mental Health Nursing, 22(4), 260-269. https:// doi.org/10.1111/jpm.12211

Çapık, A., Ejder Apay, S., \& Sakar, T. (2015). Determination of the level of distress in pregnant women. Journal of Anatolia Nursing and Health Sciences, 18(3), 196-203

Dashraath, P., Wong, J. L. J., Lim, M. X. K., Lim, L. M., Li, S., Biswas, A., Choolani, M., Mattar, C., \& Su, L. L. (2020). Coronavirus disease 2019 (COVID-19) pandemic and pregnancy. Journal of Obstetrics \& Gynecology Special Reports, 222(6), 521-531. https://doi.org/10.1016/j.ajog.2020.03.021

Fryer, K., Delgado, A., Foti, T., Reid, C. N., \& Marshall, J. (2020). Implementation of obstetric telehealth during COVID-19 and beyond. Maternal and child health journal, 24(9), 1104-1110. https://doi.org/10.1007/s10995-020-02967-7

Furber, C. M., Garrod, D., Maloney, E., Lovell, K., \& McGowan, L. (2009). Qualitative study of mild to moderate psychological distress during pregnancy. International Journal of Nursing Studies, 46(5), 669-677. https://doi.org/10.1016/j.ijnurstu.2008.12.003

Hacettepe University Institute of Population Studies 2019. (2018). Turkey demographic and health survey. Ankara, Turkey

Hall, K. S., Samari, G., Garbers, S., Casey, S. E., Diallo, D. D., Orcutt, M., Moresky, R. T., Martinez, M. E., \& McGovern, T. (2020). Centring sexual and reproductive health and justice in the global COVID-19 response. Lancet, 395(10231), 1175-1177. https://doi. org/10.1016/S0140-6736(20)30801-1

Hussein, J. (2020). COVID-19: What implications for sexual and reproductive health and rights globally? Sex Reprod Health Matters, 28(1), 1-3. https://doi.org/10.1080/26410397.2020.1746065

Kahyaoğlu Süt, H., \& Küçükkaya, B. (2020). Anxiety, depression, and related factors in pregnant women during the COVID-19 pandemic in Turkey: A web-based cross-sectional study. Perspect Psychiatr Care. https://doi.org/10.1111/ppc.12627

Karavadra, B., Stockl, A., Prosser-Snelling, E., Simpson, P., \& Morris, E. (2020). Women's perceptions of COVID-19 and their healthcare experiences: A qualitative thematic analysis of a national survey of pregnant women in the United Kingdom. BMC Pregnancy and Childbirth, 20, 600. https://doi.org/10.1186/ s12884-020-03283-2

Liu, X., Chen, M., Wang, Y., Sun, L., Zhang, J., Shi, Y., Wang, J., Zhang, H., Sun, G., Baker, P. N., Luo, X., \& Qi, H. (2020). Prenatal anxiety and obstetric decisions among pregnant women in Wuhan and Chongqing during the COVID-19 outbreak: A crosssectional study. BJOG An International Journal of Obstetrics and Gynaecology, 127(10), 1229-1240. https://doi.org/10.1111/ 1471-0528.16381

Nanda, K., Lebetkin, E., Steiner, M. J., Yacobson, I., \& Dorflinger, L. J. (2020). Contraception in the era of COVID-19. Global health Science and Practice, 8(2), 166-168. https://doi.org/10.9745/ GHSP-D-20-00119

Pop, V. J., Pommer, A. M., Pop-Purceleanu, M., Wijnen, H. A., Bergink, V., \& Pouwer, F. (2011). Development of the Tilburg Pregnancy Distress Scale: The TPDS. BMC Pregnancy and Childbirth, 11(10), 80-87. https://doi.org/10.1186/1471-2393-11-80

Rasmussen, S. A., Smulian, J. C., Lednicky, J. A., Wen, T. S., \& Jamieson, D. J. (2020). Coronavirus disease 2019 (COVID-19) and pregnancy: What obstetricians need to know. American Journal of Obstetrics \& Gynecology, 222(5), 415-426. https://doi.org/10. 1016/j.ajog.2020.02.017

Riley, T., Sully, E., Ahmed, Z., \& Biddlecom, A. (2020). Estimates of the potential impact of the COVID-19 pandemic on sexual and reproductive health in low-and middle-income countries. International Perspectives on Sexual and Reproductive Health, 16(46), 73-76. https://doi.org/10.1363/46e9020

Rochelson, B., Nimaroff, M., Combs, A., Schwartz, B., Meirowitz, N., Vohra, N., Klein, V. R., Santandreu, O., Kramer, M., Mootabar, N., Serur, E., Spiryda, L., Berlin, S., \& Chervenak, F. (2020). 
The care of pregnant women during the COVID-19 pandemicresponse of a large health system in metropolitan New York. Journal of Perinatal Medicine, 48(5), 453-461. https://doi.org/ 10.1515/jpm-2020-0175

Saccone, G., Florio, A., Aiello, F., Venturella, R., De Angelis, M. C., Locci, M., Bifulco, G., Zullo, F., \& Di Spiezio Sardo, A. (2020). Psychological impact of coronavirus disease 2019 in pregnant women. American journal of obstetrics and gynecology, 223(2), 293-295. https://doi.org/10.1016/j.ajog.2020.05.003

Schuurmans, C., \& Kurrasch, D. M. (2013). Neurodevelopmental consequences of maternal distress: What do we really know? Clinical Genetics, 83(2), 108-117. https://doi.org/10.1111/cge.12049

Sümbüloğlu, K., \& Sümbüloğlu, V. (2012). Biostatistics. (7th ed.,). Ankara

Taşkın, L. (2016). Childbirth and Women's Health Nursing. (13th ed.,). Ankara

The Royal Australian and New Zealand College of Obstetricians and Gynaecologists. (2020). Advice to obstetricians and gynaecologists, GP obstetricians (RANZCOG). Available at: https://ranzc og.edu.au/news/advice-to-obstetricians-and-gynaecologists,-gpobs Accessed: 2020 July 29.

The United Nations Population Fund (UNFPA). (2020). Technical fact sheet on COVID-19 pregnancy and maternity care services. Available at: https://turkey.unfpa.org/sites/default/files/pubpdf/ unfpa_covid19_gebelik_ve_anne_bakim_hizmetleri_turkce.pdf. Accessed 16 Nov 2020

The World Health Organization. (2020a). 2019 Novel coronavirus global research and innovation forum: Towards a research roadmap. Available at: https://www.who.int/blueprint/prioritydiseases/ keyaction/Overview_of_SoA_and_outline_key_knowledge_gaps. pdf?ua $=1$ Acccesed 27 July 2020

The World Health Organization. (2020b). Coronavirus disease (COVID-19) technical guidance: Maintaining essential health services and systems. Available at: https://www.who.int/emerg encies/diseases/novel-coronavirus-2019/technical-guidance/ maintaining-essential-health-services-and-systems Accessed 27 July 2020

Turkish Statistical Institute Press Release (TSI). (2020). Survey on information and communication technology (ICT) usage in households and by individuals 2020. No: 33679. Available at: https:// data.tuik.gov.tr/Bulten/Index?p=Hanehalki-Bilisim-Teknolojileri(BT)-Kullanim-Arastirmasi-2020-33679 Accessed 02 Feb 2021

Turrentine, M., Ramirez, M., Monga, M., Gandhi, M., Swaim, L., TyerViola, L., Birsinger, M., \& Belfort, M. (2020). Rapid deployment of a drive-through prenatal care model in response to the coronavirus disease 2019 (COVID-19) Pandemic. Obstetrics and gynecology, 136(1), 29-32. https://doi.org/10.1097/AOG.00000 00000003923

Yassa, M., Yassa, A., Yirmibeş, C., Birol, P., Ünlü, U. G., Tekin, A. B., Sandal, K., Mutlu, M. A., Çavuşoğlu, G., \& Tug, N. (2020). Anxiety levels and obsessive compulsion symptoms of pregnant women during the COVID-19 pandemic. Turkish Journal of Obstetrics and Gynecology, 17(3), 155-160. https://doi.org/10. 4274/tjod.galenos.2020.91455

Weigel, G., Frederiksen, B., Ranji, U. (2020). Telemedicine and pregnancy care. Women's Health Policy. Available at: https://www. kff.org/womens-health-policy/issue-brief/telemedicine-and-pregn ancy-care/ Accessed 16 Dec 2020

Wu, H., Sun, W., Huang, X., Yu, S., Wang, H., Bi, X., Sheng, J., Chen, S., Akinwunmi, B., Zhang, C., \& Ming, W. K. (2020). Online antenatal care during the COVID-19 pandemic: Opportunities and challenges. Journal of medical Internet research, 22(7), e19916. https://doi.org/10.2196/19916

Publisher's Note Springer Nature remains neutral with regard to jurisdictional claims in published maps and institutional affiliations. 